\title{
Factors associated with the personal assessment of college among American Indian students at a rural university
}

\author{
Terry Huffman \\ George Fox University
}

\begin{abstract}
This study examines the relationship between four independent variables (gender, age, reservation background, and cultural traditionalism) with three dependent variables (assessment of college, transition to college, and impact of college on an appreciation of Native heritage) among a sample of American Indian students attending a small, rural university. Findings include no significant relationships between any of the independent variables and the assessment of college. However, the transition to college is associated with age, reservation background, and cultural traditionalism while the impact of college on an appreciation of Native heritage is related to cultural traditionalism.
\end{abstract}

The number of American Indians attending institutions of higher learning has grown at an impressive rate (Carney, 1999; Cole \& Denzine, 2002). In fact, during the 1980s and 1990s the college enrollment among Native peoples increased by 68 percent compared to the 30 percent increase among the non-Indian population (Pavel, Skinner, Farris, Cahalan, Tippeconnie \& Stein, 1998). This trend should not necessarily surprise educators. For the first time in U.S. history the median average years of schooling has risen above 12 years for the Native population (Ward, 2005). Moreover, in only one decade the high school graduation rate among American Indian and Native Alaskans increased from 56 to 66 percent (Pavel et al., 1998).

A large proportion of American Indian students attend small, regional colleges and universities (Gilbert, 2000). Yet, while a significant number of studies have examined the higher educational experiences of American Indian students, few have specifically targeted the manner in which Native people engage small and predominantly rural institutions (Huffman, 1991).

This paper examines a number of factors associated with the general evaluation of the college experience among a sample of American Indian students. Specifically, this paper explores the relationship between four independent variables (age, gender, reservation background, and cultural traditionalism) and three dependent variables (assessment of college, transition to college, and the impact of college on an appreciation of Native heritage). Basic to the investigative effort is the question, what factors are significantly associated with each of these personalevaluative dependent variables?

Scholars have consistently focused on the issues of the general satisfaction with college, the difficulty of the transition to college, and somewhat less frequently, the impact of college on an appreciation of Native heritage. While scholars typically assume that these three personalevaluative variables are associated with a number of factors, their relationship to community background and cultural traditionalism are prominent in the literature. However, researchers have traditionally paid less attention to the relationship between these three personal-evaluative variables and such characteristics as gender and age

\section{Assessment of College}

The manner in which American Indians evaluate their college experience has gained attention among scholars. However, researchers have tended to focus on rather global assessments of the educational experiences. For instance, a common theme is the concern over inadequate preparation for higher education among Native students (James, Chavez, Beauvais, Edwards, \& Oetting, 1995; Kleinfeld, Cooper, \& Kyle, 1987). Jackson and Smith (2001) found that apprehension over the inadequate academic preparation for college was the most serious issue voiced by a sample of 22 Navajo students. Similarly, Huffman (2003) found that American Indian college students from reservations reported significantly greater academic difficulties compared to Native individuals from nonreservation areas.

However, researchers have typically not examined the perception of the merit of the college experience on a more personal level. That is, there appears to be a gap in the literature on the personal inclination to see courses as valuable, relevant, and interesting among Native students enrolled in higher educational institutions (Huffman, 2005).

\section{Reservation Background and Assessment of College}

It has been suggested that the effects of fragmented and culturally hostile education, the product of years of assimilationist educational policies has impacted the general view of western styled education among Native peoples (Child, 1996; Deloria, 1991; and Littlebear, 1992). Specifically, many culturally traditional individuals regard formal education as either irrelevant or harmful to traditional ways (Philips, 1993; Red Horse, 1980). The result has been that a number of scholars have offered substantial discussion on the seemingly ambivalent attitudes toward education pervasive among reservations populations (Deyhle \& Swisher, 1997; Ward, 1995; Wax, 1967; Wilkerson, 2005). 
On the other hand, they view their role as providing contemporary values are the product of historical experiences. Formal education has played a notorious role in the coerced assimilation of Native peoples (Wilkerson, 2005). Thus, it is reasonable to expect a great deal of variation in the regard for formal education among Native people.

In one of the few studies specifically designed to examine Native parents' attitudes toward their children's education, Robinson-Zanartu and Majel Dixon (1996) found that the value placed on formal education was connected to significant cultural concerns. For instance, these researchers reported that their sample of parents emphasized the need for educational efforts to recognize and respect the culture of their children. Moreover, these parents were much less satisfied with the nature and quality of education received at Bureau of Indian Affairs (B.I.A.) schools and, conversely, more pleased with the education delivered at tribally controlled schools. In fact, the authors report that some of the parents held the belief that B.I.A. schools actually hurt their children both academically and culturally.

How these complex views on education impact the personal evaluation of college is unclear. However, there is evidence to suggest that American Indian college students hold rather favorable views of the quality of their higher educational experiences. For instance, in a study using a sample of American Indians attending a predominately nonIndian college, Ruey-Lin Lin and associates (1988) found that the Native students actually had a more positive view of their professors and their college education than did a sample of white students.

Similarly, in an examination of how Native college students evaluate their academic experiences, Hoover and Jacobs (1992) found that a sample of undergraduate American Indian students held generally positive views about their professors and classes. Specifically, these individuals highly regarded the quality of the college instruction, held positive feelings about attending college, and were generally pleased with their own study skills. It should also be noted, however, that the sample was drawn from students attending a conference of the American Indian Science and Engineering Society and, therefore, represents a nonprobability sample. Among the more notable features of the sample is that the individuals typically were from nonreservation backgrounds, were math, natural science, or engineering majors, and had a previous relative who had attended college. Nevertheless, this study offers insight into the views of a specific group of Native students on their academic experiences. These individuals highly regarded the education they were receiving from their college or university.

In a study specifically designed to compare the academic experiences of a sample of American Indian college students from reservations with a sample of American Indian college student from nonreservation areas, Huffman (2003) found no difference in the groups on reported general satisfaction with college. This finding is particularly notable as the reservation sample of Native students reported significantly greater academic difficulties while in college.

\section{Cultural Traditionalism and Assessment of College}

The relationship between cultural traditionalism and the college experience is complex. For many years, scholars operated from the assumption that cultural assimilation was the only reasonable means for Native students to achieve in any level of formal education (Scott, 1986; Swisher \& Tippeconnic, 1999). The prevailing notion held that the more culturally assimilated an individual, the more likely he/she would value formal education. This was such a taken-for-granted assumption that there are relatively few studies that specifically focus on the relationship between cultural traditionalism and the personal assessment of college.

In a comparative analysis, Cole and Denzine (2002) found that American Indian and white students displayed comparable levels of satisfaction with college. Both groups reported rather high levels of satisfaction with the college experience. If anything, the Native sample offered more positive assessments of college compared to their white counterparts. For instance, whereas $75 \%$ of the white sample stated that they like or were enthusiastic about the college, $90 \%$ of the American Indian students indicated those same attitudes.

While this study did not examine cultural traditionalism specifically, the researchers did report an important difference in the general background between the two samples. That is, the American Indian sample contained many more first-generation college students compared to the white sample. Indeed, the difference between the two samples is striking. About $73 \%$ of the American Indian sample included first-generation college students compared to only $27 \%$ of the white sample. It is likely that many of the first-generation Native students were from reservation backgrounds (where older generations of college trained individuals are less common) and had significant exposure to Native traditionalism.

Cole and Denzine's work is especially noteworthy as it offers insight on the general level of satisfaction with college among a sample of American Indian students. It also illustrates the need for additional research in this area. In particular, studies are needed that examine the relationship between levels of personal satisfaction with college and other important variables such as gender, age, and cultural traditionalism.

Lin (1990) reported that among a sample Montana Native college students, those individuals who came from more culturally traditional families evidenced greater task achievement orientation, spent more time doing school work, and held higher grade point averages compared to American Indian students from less culturally traditional 
families. While this study did not specifically address the issue of satisfaction with college, these attributes can reasonably be associated with an individual's evaluation of the college experience.

Huffman, Sill, and Brokenleg (1986) found that the strongest predictor of academic achievement for a sample of Sioux college students was a strong cultural identity. Interestingly, an identification with cultural traditionalism was more closely associated with academic achievement than any other factor including family income, parental encouragement, and high school GPA. Once again, while the personal evaluation of college is not the focus of the study, this investigation suggests that cultural traditionalism and assessment of higher education must be fundamentally linked.

\section{The Transition to College}

The nature of the transition to college for Native students is a popular theme in the American Indian education literature. Numerous scholars have commented on the uneasy, unfamiliar, and unsettling transition Native individuals (especially more culturally traditional people) experience when entering institutions of higher learning.

\section{Reservation Background and the Transition to College}

A number of studies have examined the relationship between coming from a reservation and the transition to college. The findings of these studies are rather consistent. Namely, American Indians from reservations tend to experience a more difficult transition to college compared to those who are not from reservation areas. For instance, Benjamin and his associates (1993) found substantial difficulties with the transition to college among Native students from reservation areas. Moreover, these individuals experienced difficulty with the transition to college regardless to how well they had academically performed in high school.

Likewise, Huffman (2003) too found Native students from reservations reported greater difficultly in the transition to college compared to those from nonreservation areas. This was the case despite the fact that the two groups were comparable in terms of postsecondary academic success.

Using a qualitative study with 16 American Indian students at a predominately white institution, Janis Taylor (2005) also found pervasive and perplexing difficult transitions to college. Prominent among the experiences of these students were feelings of cultural exclusion and personal/social isolation. The physical separation from their home, especially for those from reservations, exacerbated these perceptions.

person for Hispanic parents in their efforts to Cultural

Traditionalism and the Transition to College
For years a prevailing assumption found in the American Indian education literature was that cultural traditionalism represents a serious barrier in the formal educational efforts aimed at Native peoples (Cleary \& Peacock, 1998; Ward, 2005). This approach to American Indian education is referred to as the deficit model (Swisher \& Tippeconnic, 1999). Basic to this theoretical approach is the view that Native peoples suffer from a number of social pathologies (including poor academic achievement) because their culture is deficit to serve them in the face of the demands imposed by modern society. As such, it was necessary that Native people abandon the restraining elements of their cultures and fully assimilate into the dominant society. Consequently, numerous educators advocated the solution to the academic problems besetting Native peoples to be their assimilation into the societal mainstream.

Scott (1986) referred to the retention of Native cultural traditionalism in academic pursuits as the "difficult situation" (p. 381). Specifically, Scott argued that educational institutional policies have tended to reflect the basic assumption inherent in the deficit model and have worked to encourage American Indians students to culturally assimilate into the culture of the university. These efforts resulted in unfortunate consequences for Native students. Indeed, Scott found that retention of American Indian traditionalism represented the most serious factor inhibiting greater academic achievement among a sample of American Indian college students:

The data confirm that being a "cultural Indian" reduces the likelihood of academic success . . . those committed to Indian ways are less likely to become integrated into the university community, and consequently less likely to succeed (p. 381).

The deficit model is not as highly regarded today as in years past and its central assertion has come under strong attack (Huffman, 2005; Swisher \& Tippeconnic, 1999; Van Hamme, 1996). In fact, recent researchers have reported that an attachment to Native cultural traditions is associated with greater academic success at all educational levels (James, et al., 1995; Whitbeck et al., 2001; Vadas, 1995).

Nevertheless, there remains substantial evidence that, initially at least, a strong identification with Native cultural traditional is associated with greater transitional problems with higher education. In a qualitative research effort, Huffman (2008) reported significant and pervasive issues with the initial transition to college among the more culturally traditional American Indian students. These difficulties involved a variety of issues including financial hardships, academic problems, feelings of alienation and most notably assorted cultural conflicts. Conversely, the transition to college was significantly less problematic for the more culturally assimilated Native students. However, with time, a strong identification with cultural traditionalism 
actually contributed to the academic persistence and success among many of the Native students.

Similar to the Huffman study, Schiller and Gaseoma (1993) too reported serious difficulties transitioning to college among a sample of American Indian students. Among the most problematic concerns voiced by the individuals in their study was the cultural conflict they experienced. Yet, like Huffman, these researchers too found that eventually cultural traditionalism facilitated academic achievement.

\section{Impact of College on the Appreciation of Native Heritage}

Recently scholars have begun to examine the impact of being in college has on a personal appreciation of Native heritage. Simply there is a growing body of work documenting that many Native students enrolled in mainstream higher educational institutions gain a greater awareness of and appreciation for American Indian history, cultures, and traditions (Huffman, 2003; Taylor, 2005).

\section{Reservation Background and Impact \\ of College on the Appreciation of Native Heritage}

Using in-depth personal interviews to explore the higher educational experiences of 31 American Indian women, Franci Taylor (2005) documented the importance that being enrolled in college can have on an appreciation for Native heritage. Notable among her findings was that the individuals from reservation areas in particular voiced a keen regard for Native traditions. Moreover, their immersion in the mainstream higher educational environment served to enhance their embracement of Native heritage.

In a similar study utilizing 22 Navajo students, Jackson and Smith (2001) reported that a connection to one's homeland while in college was vital to the individuals in their study. Specifically, the students from reservations indicated that while leaving their homes was extremely difficult, it was imperative that they maintain a strong connection to the reservation. In turn this attachment helped to foster a greater appreciation of who they were and what their cultural heritage involves.

While some qualitative studies have suggested a relationship between coming from a reservation area and an enhanced appreciation for Native heritage, at least one quantitative research study did not document such a relationship. In a study involving 37 American Indian upperclassmen, Huffman and Ferguson (2007) reported that reservation/nonreservation background was not significantly correlated with the reported appreciation of Native American heritage. That is, those upperclassmen from reservations were no more likely to report a greater appreciation for their heritage than those not from reservation areas.

\section{Cultural Traditionalism and Impact of College on Appreciation of Native Heritage}

In a study on cultural conflict among Native college students, Schiller and Gaseoma (1993) reported pervasive serious and imposing cultural inconsistencies among the participants of their study. Nevertheless, the identification with Native culture and traditions facilitated greater academic success among the students. Indeed, cultural traditionalism coupled with the emerging appreciation for Native cultural ways served as an important part of what the researchers refer to as "creative strategies" for dealing with the demands of mainstream higher education (p. 50).

Likewise in their qualitative work focusing on the postsecondary experiences among 22 Navajo individuals, Jackson and Smith (2001) also documented the tendency for strong cultural ties to be associated with an appreciation for Native heritage while enrolled in college. These researchers reported that their respondents clearly recognized the strength offered by their cultural heritage in their endeavors after high school.

\section{Method}

The data used for this study come from a survey on attitudes, perceptions, and experiences among American Indians student attending a small, rural state university in the upper-midwest. The university enrolls approximately 2,700 students. About $4 \%$ of the student enrollment is Native students. For a five year period each American Indian enrolled in the university was sent information on the nature and purpose of the research, an invitation to participate in the study, the survey instrument, and a letter of consent. A total of 232 Native students enrolled in the university during the course of the research activity and 101 of the individuals returned surveys. However, only 86 surveys were completed appropriately to be used in the analysis for this paper. Specifically, 15 of the questionnaires contained missing data on various variables and, therefore, were excluded from the analysis.

Virtually all the respondents were Dakota, Lakota, or Nakota. However, a number of Ojibwa and Shoshone individuals were included in the research as well.

\section{Human Subjects Research Ethics}

The university's American Indian student leadership initiated this research effort. It was their specific desire to obtain greater information on the nature of the higher educational experience for the campus Native students. This study followed all human subjects research policies established by the university and the American Sociological Association's code of ethics. 


\section{Operationalization of Variables}

All independent and dependent variables were measured either through the use of a single item question (coded as a dummy variable), a single Likert item, or created with a scale using several questionnaire items. Specifically, the variables were operationalized and measured in the following manner:

Independent variables

- $\quad$ Gender (GEN) - the gender identification offered by the student (coded: 0 = male, 1 = female).

- Age (AGE) - the self-reported age indicated by the student (coded: $1=20$ years and younger; $2=21$ to 24 years; 3 = 25 to 29 years; $4=30$ years old).

- Reservation Background (RES) - the self-reported indication of having been reared on a reservation (coded: 0 = no, 1 = yes).

- Cultural Traditionalism (CRT) - the score on a scale created by combining three questionnaire items (see Table 1).

Dependent variables

- Assessment of College (AOC) - the score on a scale created by combining three questionnaire items (see Table 1).

- Transition to College (TTC) - the self-reported evaluation indicated by the response to the question, "Generally, how would you describe your cultural transition to college during your first year at school?” (coded: 1 = no cultural difficulties; 2 = mild cultural difficulties; 3 = complex cultural difficulties; and 4 = severe cultural difficulties).

- Impact of College on an Appreciation of Native Heritage $(\mathrm{ANH})$ - the self-reported evaluation indicated by the response to the question "Overall, I feel that my experiences in college have helped me gain a greater appreciation of my American Indian heritage” (coded: 1 = strongly disagree; 2 = disagree; 3 = agree; 4 strongly agree).

It should be noted that two of the variables (cultural traditionalism and assessment of college courses) were created through the construction of a scale. Table 1 presents the specific questionnaire items included in each of these scales along with the Cronbach's Coefficient Alpha. Generally, these scales performed well under tests of reliability. The scale cultural traditionalism revealed a reliability of .721 while the scale assessment of college courses evidenced a reliability of .624 .

\section{Statistical Procedures}

Statistical analysis of the data consisted of Pearson correlation, regression analysis, analysis of variance, and $t$ tests. Pearson correlations and regression analysis provide ways for exploring the general relationships between variables. Regression analysis also indicate the amount of variance for each dependent variable explained by the independent variables. Further, given the mixed findings reported in the literature on the relationship between reservation background and the dependent variables, a $t$-test was conducted as a means to compare those students from reservations with those from nonreservation areas. Finally, due to the little attention in the American Indian education literature on gender and age issues, $t$-tests and analysis of variance were performed to explore for gender and age differences on the dependent variables.

\section{Findings}

\section{Correlations}

Table 2 presents the zero-order correlations. Analysis of the data revealed a number of significant correlations between the independent variables and dependent variables. Specifically, transition to college (TTC) is significantly correlated with being older (AGE .236, $p<.05$ ), coming from a reservation (RES .386, $p<.01$ ), and being more culturally traditional (TTC .341, $p<.01$ ). Similarly, the impact of college on an appreciation of Native heritage (ANH) is significantly correlated with being older (AGE .235, $p<.05$ ) and being more culturally traditional (TTC .349, $p<.01$ ). The dependent variable assessment of college (AOC) is not statistically significantly correlated with any of the independent variables or other dependent variables.

Beyond the correlations between the independent and dependent variables, there are two other notable associations. First, there is a significant correlation between the independent variable age (AGE) and the independent variable cultural traditionalism (CRT) $(.369, p<.01)$. Second there is a significant correlation between the dependent variable transition to college (TTC) and the dependent variable impact of college on an appreciation of Native heritage (ANH) $(.417, p<.01)$.

The zero-order correlations seem to indicate that older Native students, those from reservations, and individuals who adhere to more culturally traditional ways and values experience a more difficult transition to college. Additionally, older students and those from reservations also are more likely to indicate that being in college positively impacts their appreciation of Native heritage. However, the general assessment of college is not significantly related to 
Table 1

Scales and Reliability Coefficients

Cultural Traditionalism Scale (Reliability $=.721$ )

1) Do you speak a Native American language?

$1=$ not at all and not attempting to learn

$2=$ not at all but am attempting to learn

$3=$ only a very little

4 = moderately

5 = fluently

2) Did you participate in Native American ceremonies (such as dances, give-aways; powwows, etc.) before coming to college?

$$
\begin{aligned}
& 1=\text { never } \\
& 2=\text { occasionally } \\
& 3=\text { frequently }
\end{aligned}
$$

3) Have you participated in Native American ceremonies (such as dances, give-aways; powwows, etc.) while you have been in college?

$$
\begin{aligned}
& 1=\text { never } \\
& 2=\text { occasionally } \\
& 3=\text { frequently }
\end{aligned}
$$

Assessment of College Scale (Reliability = .624)

1) Generally I find college courses to be interesting.

$$
\begin{aligned}
& 1=\text { strongly disagree } \\
& 2=\text { disagree } \\
& 3=\text { agree } \\
& 4=\text { strongly agree }
\end{aligned}
$$

2) I think college courses are relevant to my future.

$$
\begin{aligned}
& 1=\text { strongly disagree } \\
& 2=\text { disagree } \\
& 3=\text { agree } \\
& 4=\text { strongly agree }
\end{aligned}
$$

3) College has helped me gain valuable knowledge.

$$
\begin{aligned}
& 1=\text { strongly disagree } \\
& 2=\text { disagree } \\
& 3=\text { agree } \\
& 4=\text { strongly agree }
\end{aligned}
$$

any of the more prominent independent variables commonly identified in the literature.

\section{Regression Analysis}

The findings produced by regression analysis are consistent with the general patterns evidenced by the zero- order correlations (Table 3). Specifically, none of the independent variables demonstrate significant predictive ability of the dependent variable assessment of college (AOC). Collectively these variables are very weakly associated with this variable and account for only about 5\% of the variance in assessment of college. 
Table 2

Zero-Order Correlations

\begin{tabular}{llllllll}
\hline Variables & GEN & AGE & RES & CRT & AOC & TTC & ANH \\
\hline GEN & 1.00 & & & & & & \\
AGE & .159 & 1.00 & & & & & \\
RES & .116 & .100 & 1.00 & & & & \\
CRT & .159 & $.369^{* *}$ & -.015 & 1.00 & & & \\
AOC & .109 & .185 & .017 & .145 & 1.00 & & \\
TTC & .195 & $.236^{*}$ & $.386^{* *}$ & $.341^{* *}$ & -.031 & 1.00 & \\
ANH & .001 & $.235^{*}$ & .149 & $.349^{* *}$ & .049 & $.417^{* *}$ & 1.00 \\
\hline
\end{tabular}

${ }^{*} p<.05 ; * * p<.01$

GEN - Gender ( 0 = male; 1 = female $)$

AGE - Age ( $1=20$ years and younger; $2=21$ to 24 years; $3=25$ to 29 years; $4=30$ years old $)$

RES - Reservation Background $(0=$ no, $1=$ yes $)$

CRT - Cultural Traditionalism (lower scores indicate less cultural traditionalism)

AOC - Assessment of College (lower scores indicate less favorable evaluation of college courses)

TTC - Transition to College (lower scores indicate less difficult transition to college)

ANH - Impact of College on an Appreciation of Native Heritage (lower scores indicate less impact)

Table 3

Multiple Regression Analysis t-Tests

\begin{tabular}{|c|c|c|}
\hline & Unstandardized Beta & Standardized Beta \\
\hline \multicolumn{3}{|l|}{ Assessment of College } \\
\hline GEN & .211 & .074 \\
\hline AGE & .178 & .144 \\
\hline RES & -.013 & -.004 \\
\hline CRT & .053 & .081 \\
\hline $\mathrm{R}$ & $\mathrm{R}^{2}$ & Adjusted $\mathrm{R}^{2}$ \\
\hline .215 & .046 & .001 \\
\hline \multicolumn{3}{|l|}{ Transition to College } \\
\hline GEN & .242 & .092 \\
\hline AGE & .082 & .072 \\
\hline RES & .997 & $.373^{* *}$ \\
\hline CRT & .183 & $.305^{* *}$ \\
\hline $\mathrm{R}$ & $\mathrm{R}^{2}$ & $\mathrm{R}^{2}$ Adjusted \\
\hline .532 & .283 & .247 \\
\hline
\end{tabular}


Table 3, continued

Unstandardized Beta Standardized Beta

Appreciation for

Native Heritage

\begin{tabular}{|c|c|c|c|}
\hline & GEN & -.149 & -.086 \\
\hline & AGE & .086 & .115 \\
\hline & RES & .270 & .153 \\
\hline & CRT & .128 & $.323 * *$ \\
\hline $\begin{array}{c}\mathrm{R} \\
403\end{array}$ & & $\begin{array}{c}\mathrm{R}^{2} \\
.162\end{array}$ & $\mathrm{R}^{2}$ Adjusted \\
\hline
\end{tabular}

The dependent variable impact of college on an appreciation of Native heritage (ANH) is significantly associated with only one independent variable, cultural traditionalism (CRT, .323, $p<.01$ ) (Table 3) Taken together the four independent variables account for about $16 \%$ of the variance in levels of appreciation of Native heritage.
Table 4 presents the $t$-test comparison of the dependent variables by reservation background. Notable among these findings is that only the transition to college is significantly different for those who come from reservation backgrounds as opposed to those students not from reservation areas $(t=-$ $3.84, p<.01)$. Specifically, those Native students from

Table 4

t-tests Dependent Variable by Reservation Background

\begin{tabular}{|c|c|c|c|c|c|}
\hline Variable & Reservation Background & Mean & S.D. & $\underline{\mathrm{N}}$ & $\underline{\text { Result }}$ \\
\hline \multirow{2}{*}{ Assessment of College } & Yes & 10.04 & 1.40 & 28 & \multirow{2}{*}{$t=-.159$, n.s. } \\
\hline & No & 10.09 & 1.37 & 58 & \\
\hline \multirow[b]{2}{*}{ Transition to College } & Y & 157 & 96 & 28 & \multirow{2}{*}{$t=-3.84, p<.01$} \\
\hline & No & 260 & 1.26 & 58 & \\
\hline & & & & & \\
\hline \multirow[b]{2}{*}{ Appreciation of College } & Yes & 2.86 & .80 & 28 & \multirow[b]{2}{*}{$t=-1.38$, n.s. } \\
\hline & No & 3.12 & .84 & 58 & \\
\hline
\end{tabular}

reservations reported statistically significantly higher levels of difficulty in the transition to college. However, the American Indian students in this sample from reservation and nonreservation areas are not significantly different in their assessments of college or on the reported impact of college on an appreciation of their Native heritage.

There are no statistically significant differences between the genders in this sample on the three dependent variables (Table 5). In fact, only on the variable transition to college is there a slight difference in the means between the genders (1.93 for men and 2.45 for women). That is, women reported somewhat greater difficulty in the transition to college compared to men. However, this difference is not statistically significant at the .05 level.

\section{Analysis of Variance}

The analysis of variance findings reveal that the three dependent variables do not significantly vary by the age groupings used in this study (Table 6). Those students who are 30 years or older reported slightly more positive assessments of college, more difficult transitions to college, and greater impact of college on an appreciation of Native heritage compared to the other age groupings. Yet, none of these differences is great enough to be statistically significant. 
Table 5

t-Tests Dependent Variables by Gender

\begin{tabular}{cccccc}
\hline Variable & Gender & Mean & S.D. & $\mathrm{N}$ & \\
\hline $\begin{array}{c}\text { Assessment } \\
\text { of College }\end{array}$ & Male & 9.87 & 1.20 & 30 & $t=-.101$, \\
& Female & 10.18 & 1.45 & 56 & n.s. \\
Transition & Male & 1.93 & 1.17 & 30 & $t=-1.83$, \\
to College & Female & 2.45 & 1.28 & 56 & n.s. \\
& & & & & \\
Appreciation & Male & 3.03 & .89 & 50 & $t=-.013$, \\
of College & Female & 3.04 & .81 & & n.s. \\
\hline
\end{tabular}

Table 6

Analysis of Variance Dependent Variables by Age

\begin{tabular}{|c|c|c|c|c|c|c|c|c|}
\hline & $\mathrm{N}$ & Mean & S.D. & & $\begin{array}{l}\text { Sum of } \\
\text { Squares }\end{array}$ & Df & $\begin{array}{l}\text { Mean } \\
\text { Square }\end{array}$ & $F$ \\
\hline \multicolumn{9}{|l|}{$\begin{array}{l}\text { Assessment } \\
\text { of College }\end{array}$} \\
\hline 20 or younger & 13 & 9.38 & 1.61 & Between Groups & 7.97 & 3 & 2.66 & 1.44, n.s. \\
\hline 21 to 24 & 19 & 10.16 & 1.34 & & & & & \\
\hline 25 to 29 & 20 & 10.05 & 1.70 & Within Groups & 151.61 & 82 & 1.85 & \\
\hline 30 or older & 34 & 10.29 & 1.03 & & & & & \\
\hline Total & 89 & 10.07 & 1.37 & Total & 159.58 & 85 & & \\
\hline \multicolumn{9}{|l|}{$\begin{array}{l}\text { Transition } \\
\text { to College }\end{array}$} \\
\hline 20 or younger & 13 & 2.00 & 1.41 & Between Groups & 10.13 & 3 & 3.38 & 2.22, n.s. \\
\hline 21 to 24 & 19 & 1.74 & 1.10 & & & & & \\
\hline 25 to 29 & 20 & 2.40 & 1.27 & Within Groups & 124.72 & 82 & 1.52 & \\
\hline 30 or older & 34 & 2.59 & 1.21 & & & & & \\
\hline Total & 89 & 2.27 & 1.26 & Total & 134.85 & 85 & & \\
\hline \multicolumn{9}{|l|}{$\begin{array}{l}\text { Appreciation of } \\
\text { Native Heritage }\end{array}$} \\
\hline 20 or younger & 13 & 2.85 & .69 & Between Groups & 4.04 & 3 & 1.35 & 2.01, n.s. \\
\hline 21 to 24 & 19 & 2.79 & .92 & & & & & \\
\hline 25 to 29 & 20 & 2.95 & .83 & Within Groups & 54.86 & 82 & .67 & \\
\hline 30 or older & 34 & 3.29 & .80 & & & & & \\
\hline Total & 89 & 3.03 & .83 & Total & 58.90 & 85 & & \\
\hline
\end{tabular}

\section{Discussion}

The findings indicate several important patterns in the experiences of this sample of Native students enrolled in a rural university. First, none of the independent variables evidenced a significant relationship with the dependent variable assessment of college. This rather innocuous appearing finding is actually quite notable. That is, the 
literature treats the evaluation of the college experience among Native students in a variety of ways. Most studies explore the general college experience and do not necessarily focus on a personal assessment of the academic value to the student. Few studies like Lin (1990) specifically examine the personal appraisal of the academic merit among Native students.

The analysis of the data included in this study suggests that such personal evaluations are not necessarily connected to important characteristics such as age, reservation background or cultural traditionalism. The evidence indicating that Native students possessing differing levels of adherence to cultural traditionalism are similar in the way they assess the academic value of college is itself an important insight. In the past, some educators regarded culturally traditional individuals as less inclined to value formal education. The findings provided by this study suggest otherwise. There is no significant relationship in the personal assessment in the value of college education and cultural traditionalism among the American Indian students involved in this research. What is much less clear is how American Indian students compare to white and other minority students on personal assessments of the academic value of their college experience. Research on this issue would be very informative.

The results from the data analysis clearly reveal that greater difficulty in the transition to college is associated with coming from a reservation background and greater adherence to Native cultural traditionalism. These relationships are supported by the findings from the zeroorder correlations and the regression analysis. The $t$-test analysis also partially support these relationships. Those students from reservations reported significantly greater difficulty in the transition to college compared to those individuals from nonreservation areas.

However, previous research, especially findings produced from qualitative studies, indicate that the relationship between these variables is complex and dynamic. The findings on the relationship between cultural traditionalism, reservation background, and the transition to college should be considered in conjunction with other important research insights. Specifically, there is evidence that, although many culturally traditional individuals from reservations experience extremely difficult transitions to college, a strong identification with American Indian cultural traditions can eventually act to facilitate higher educational persistence. That is, the use of cultural traditions and ethnic identity social psychologically anchors an individual and provides him/her with a sense of purpose (Huffman, 2008; Schiller \& Gaseoma, 1993). Thus, while the findings on the transition to college and cultural traditionalism are important, they are likely only part of the wider higher educational experiences among many Native students.

The findings of this study also document that the impact of college on an appreciation for Native heritage is associated with higher levels of cultural traditionalism. The zero-order correlations and multiple regression analysis indicate significant relationships between these variables. Moreover, the zero-order correlations provide partial evidence to suggest that older students also report a greater appreciation for Native heritage while in college. These results are especially noteworthy because the possibility that college enrollment can operate on the manner Native students view their cultural heritage is not well researched and understood.

These findings are, however, consistent with insights provided by some qualitative research efforts. As discussed above, previous research studies have found that strong identification with cultural traditionalism can enhance academic persistence for American Indian students. Although the complex reasons for this is beyond the scope of this paper, it is likely that the demanding nature of the academic endeavor at a non-Indian institution lies at the heart of the situation. That is, academic persistence for many Native students necessarily involves the successful management of troubling encounters with cultural conflict. An ancillary finding produced by this research is that a more difficult transition to college (likely involving cultural discrepancies) was significantly correlated with a greater appreciation for Native heritage $(.417, p<.01)$. It is reasonable to assume that the resolution of cultural disjunctions would also work to enhance an appreciation of one's ethnic heritage (Huffman, 2008).

\section{Conclusions}

American Indians are a culturally and demographically diverse group. Much of the current research has been conducted at major research universities enrolling sizable numbers of American Indian students. However, the experiences of Native students attending smaller, rural colleges and universities are equally complex and important. There remains much to learn about the nature of the higher educational experiences for these individuals and both quantitative and qualitative research efforts are necessary.

Specifically, research that examines a variety of dimensions of the assessment of college would be helpful. There are many different aspects of the college experience. Educators would benefit from insight on what components Native students generally evaluate both positively and negatively. This knowledge would aid in the manner in which institutions of higher learning serve American Indian students. Greater understanding of gender, age, reservation and nonreservation differences would potentially yield important information as well.

However, efforts designed to more fully understand the nature of cultural traditionalism, the maintenance and use of ethnic identity, and the role that Native heritage plays in the college experience are especially needed. The deficit model with its assimilationist assumptions established an early theoretical tradition in American Indian education 
scholarship (Swisher \& Tippeconnic, 1999). However, with the generally accepted demise of this perspective, it is important that researchers develop new theoretical frameworks for understanding the Native higher educational experience. Basic to these new theoretical directions will most certainly be the role performed by cultural traditionalism and strong cultural identification in the educational outcomes among Native students.

\section{References}

Benjamin, D.P., Chambers, S., \& Reiterman, G. (1993). A focus on American Indian college persistence. Journal of American Indian Education, 32(2), 24-40.

Carney, C.M. (1999). American Indian higher education in the United States. New Brunswick, NJ: Transaction Publishers.

Child, B. (1996). Runaway boys, resistant girls: Rebellion at Flandreau and Haskell, 1900-1940. Journal of American Indian Education, 35(3), 49-57.

Cleary, L.M. \& Peacock, T.D. (1998). Collected wisdom: American Indian education. Needham Heights, MA: Allyn \& Bacon.

Cole, J.S. \& Denzine, G.M. (2002). Comparing the academic engagement of American Indian and white college students. Journal of American Indian Education, 41(1), 19-34.

Deloria, V. (1991). Indian education in America. Boulder, CO: American Indian Science and Engineering Society.

Deyhle, D. \& Swisher, K. (1997). Research in American Indian and Alaska Native education: From assimilation to self-determination. In M. Apple (Ed.), Review of Research in Education, Vol. 22, (pp. 113-194). Washington, D.C.: American Educational Research Association.

Gilbert, W.S. (2000). Bridging the gap between high school and college. Journal of American Indian Education, 39(3), 36-58.

Hoover, J. \& Jacobs, C. (1992). A survey of American Indian college students: Perceptions toward their study skills/college life. Journal of American Indian Education, 30(2), 25-34.

Huffman, T.E. (1991). The experiences, perceptions, and consequences of campus racism among Northern Plains Indians. Journal of American Indian Education, 30(2), 25-34.

Huffman, T.E. (2003). A comparison of personal assessments of the college experience among reservation and nonreservation American Indian students. Journal of American Indian Education, 42(2), 1-16.

Huffman, T.E. (2005, November). Academic achievement through cultural autonomy: Enhancing higher educational persistence for culturally traditional American Indians. Paper presented at the meeting of the
People of Color in Predominately White Institutions conference, Lincoln, Nebraska.

Huffman, T. E. (2008). American Indian higher educational experiences: Cultural visions, personal journeys. New York: Peter Lang Publishing.

Huffman, T. \& Ferguson, R. (2007). Evaluation of the college experience among American Indian upperclassmen. Great Plains Research, 17(1), 61-71.

Huffman, T.E., Sill, M.L., \& Brokenleg, M. (1986). College achievement among Sioux and White South Dakota students. Journal of American Indian Education, 25(2), 32-38.

Jackson, A.P. \& Smith, S.A. (2001). Postsecondary transitions among Navajo Indians. Journal of American Indian Education, 40(2), 28-47.

James, K., Chavez, E., Beauvais, F., Edwards, R., \& Oetting, G. (1995). School achievement and dropout among Anglo and Indian females and males: A comparative examination. American Indian Culture and Research Journal, 19(3), 181-206.

Kleinfeld, J., Cooper, J., \& Kyle, N. (1987). Postsecondary counselors: A model for increasing Native American’ college success. Journal of American Indian Education, 27(3), 9-16.

Lin, R.L. (1990). Perceptions of family background and personal characteristics among Indian students. Journal of American Indian Education, 29(3), 19-28.

Lin, R.L., LaCounte, D. \&, Eder, J. (1988). A study of Native American students in a predominantly white college. Journal of American Indian Education, 27(3), 8-15.

Littlebear, D. (1992). Getting teachers and parents to work together. In J. Reyhner (Ed.), Teaching American Indian students (pp.104-111). Norman, OK: University of Oklahoma Press.

Pavel, D.M., Skinner, R., Farris, E., Cahalan, M., Tippeconnie, J., Stein, W. (1998). American Indian and Alaska Natives in postsecondary education. Washington, D.C.: U.S. Department of Education.

Philips, S.U. (1983). The invisible culture: Communication and community on the Warm Springs Indian reservation. New York: Longman.

Red Horse, J.G. (1980). Family structure and value orientation in American Indians. Social Casework: The Journal of Contemporary Social Work, 61(8), 462-467.

Robinson-Zanartu, C. \& Majel-Dixon, J. (1996). Parent voices: American Indian relationships with schools. Journal of American Indian Education, 36(1), 33-54.

Schiller, P. \& Gaseoma, L. (1993). Analysis of self-reported strategies for successful adjustment to higher education by bicultural Native American students. In Y.I. Song \& E.C. Kim (Eds.), American mosaic: Selected readings on America's multicultural heritage (44-54). Englewood Cliffs, NJ: Prentice-Hall.

Scott, W.J. (1986). Attachment to Indian culture and the “difficult situation.” Youth \& Society, 17(4), 381-395. 
Swisher, K. \& Tippeconnic, J.W. (1999). Research to support improved practice in Indian education. In K.G. Swisher \& J.W. Tippenconnic (Eds.), Next steps: Research and practice to advance Indian education (pp. 295-307). Charleston, WV: ERIC Clearinghouse on Rural Education and Small Schools.

Taylor, F.L. (2005). American Indian women in higher education: Is Tinto's model applicable? Unpublished master's thesis, Montana State University.

Taylor, J. (2000, April). Portrait in alienation: Native American students on a predominantly white campus. Paper presented at the CIC Graduate Research Conference. Iowa City, Iowa.

Ward, C. J. (1995). American Indian high school completion in rural southeastern Montana. Rural Sociology, 60(3), 416-434.

Ward, C.J. (2005). Native Americans in the school system: Family, community, and academic achievement.
Lanham, MD: AltaMira Press.

Wax, R. (1967). The warrior dropouts. Lawrence, KS: University of Kansas Press.

Whitbeck, L., Hoyt, D., Stubben, J., \& LaFromboise, T. (2001). Traditional culture and academic success among American Indian children in the upper midwest. Journal of American Indian Education, 40(2), 48-60.

Wilkinson, C. (2005). Blood struggle: The rise of Modern Indian nations. New York: W.W. Norton \& Company.

Vadas, R. (1995). Assessing the relationship between academic performance and attachment to Navajo culture. Journal of Navajo Education, 12(4), 16-25.

Van Hamme, L. (1996). American Indian cultures and the classroom. Journal of American Indian Education, 35(2), 21-34. 